\title{
Evolutionary Populations for Sustainable Food Security and Food Sovereignty
}

\author{
Salvatore Ceccarelli, Stefania Grando, Maedeh Salimi, \\ and Khadija Razavi
}

\begin{abstract}
Two mechanisms in plant breeding are thought to diminish crop diversity: the displacement of landraces by "improved" varieties, and a bias towards varieties developed under a high-input management regime. This multinational study examines how genetic diversity can be restored through evolutionary plant breeding: enabling plants under cultivation to evolve via natural selection pressure and adapt to the environment. The authors first present findings from research in Iran. Here, in participation with institutions, farmers selected barley, rice and wheat varieties from evolutionary populations for cultivation and used them outright as "smart crops" with all-around benefits for the environment, human health and farming income. A similarly successful project in Italy led to six more in countries across Africa, Asia and the Near East. Ultimately, the authors conclude, such "evolutionary-participatory"
\end{abstract}

S. Ceccarelli $(\bowtie) \cdot$ S. Grando

Ascoli Piceno, Italy

M. Salimi · K. Razavi

CENESTA, Tehran, Iran

Y. Nishikawa and M. Pimbert (eds.), Seeds for Diversity and Inclusion, https://doi.org/10.1007/978-3-030-89405-4_8 
plant breeding enables farmers to manage genetic diversity autonomously. While the seeds produced have yet to meet the requirements of seed laws, new rules emerging in Europe could enable organic farmers to adopt the approach from 2022 .

Keywords Crop diversity · Evolutionary plant breeding · Iran · Italy · Seed autonomy

\subsection{INTRODUCTION}

Plant breeding is thought to be a cause of the decline in agrobiodiversity through two interconnected mechanisms: the displacement of myriad landraces by a few improved varieties (Dwivedi et al., 2016; van der Wouw et al., 2010), and the centralized organization of most breeding programmes in which selection takes place within one or a few wellmanaged research stations. The crops in the research stations are well managed (fertilized, protected against weeds, diseases and insects, and irrigated when necessary) because under those conditions selection is believed to be more efficient (Baranski, 2015; Ceccarelli, 1989). This belief, however, is not necessarily true.

Inevitably, the varieties produced by these breeding programmes can perform well if managed as they were during the selection process. This has two consequences: first, the dissemination of varieties will be accompanied by an increase in the use of inputs such as synthetic fertilizers and other chemicals; and secondly, as the inputs effectively minimize the differences between locations, the same varieties will be able to perform well widely, causing an overall decline of crop diversity (Bonnin et al., 2014).

The loss of agrobiodiversity is associated with increased vulnerability both to climate change (Keneni et al., 2012), including climate extremes (Isbell et al., 2015), and to agricultural pests (Díaz et al., 2006; Fisher et al., 2018). This situation is growing even more alarming because of the complexity of climate change, which involves not only a change in temperature and rainfall but also in the type and spread of insects, diseases and weeds (Ceccarelli \& Grando, 2020a). 


\subsection{Bringing Back Diversity in Farmers' Fields: Participatory Plant Breeding}

Participatory research has been formally proposed in the early 1980s (Rhoades \& Booth, 1982) by social scientists, based on the principle of involving users and clients in research and development (Ceccarelli \& Grando, 2020b). When applied to plant breeding, it was construed as a more socially equitable model. Along with its social dimension, participatory plant breeding (PPB) is also more efficient: its impact is measured not only as genetic gains and number of varieties released, but also as customer acceptance of the final product, a rise in agrobiodiversity and a higher benefit/cost ratio (Ceccarelli, 2015).

An example of farmers' assessment of the benefits of PPB was the International Farmers' Conference organized by the International Center for Agricultural Research in the Dry Areas (ICARDA) in May 2008, 13 years after PPB had started in Syria by the barley improvement program of the centre with the financial assistance of GTZ (German Corporation for Technical Cooperation) now GIZ. The conference involved more than 50 farmers from Algeria, Canada, Egypt, Eritrea, France, Iran, Jordan and Syria, and used different methodologies, including storytelling, to facilitate sharing their agricultural knowledge and thus capture their thoughts about PPB. The main findings (Galiè et al., 2009) suggest that farmers perceived that their participation in key decisional stages of plant breeding enhanced their self-esteem, increased their knowledge and communication skills, and changed their perception of gender roles.

PPB has been very successful among farmers' communities in Syria, Jordan, Yemen, Egypt, Tunisia, Morocco, Eritrea, Ethiopia and Iran (Ceccarelli et al., 2013) but not well accepted by several public research institutions, with a few exceptions. The reasons for this generalized institutional reluctance to adopt PPB have been discussed recently by Salvatore Ceccarelli and Stefania Grando (2020b). They range from conventional and biotechnological methods dominating university curricula on plant breeding to the reward system in public institutions, which is still largely based on the number of varieties released. A more fundamental reason is the reluctance to accept the paradigm shift that PPB inevitably implies in "seed sovereignty" and, consequently, "food sovereignty" (Ceccarelli \& Grando, 2020b). In several countries, it has been reported that any institutional support was mostly of a personal nature and ended when the person left. 
One notable aspect of the PPB programmes was the farmers' interest in experimenting by mixing different varieties of the same crop starting in 2007, particularly in Syria and Iran. Before the project, as with most farmers in the Near East, they were accustomed to receiving a few uniform varieties from the national research systems. In Syria, farmers' initial exposure to mixtures of different varieties was partly associated with the system of compensation for land use we developed in consultation with farmers. In fact, farmers agreed on a given amount of grain as fair compensation for the land and the time they dedicated to the experiments. Sometimes the grain was a mixture that, although intended as animal feed, was used at least in part as seed. It was in this way that farmers started to become aware of the advantages in growing mixtures such as better and more stable grain yield.

Syrian farmers also occasionally attended events at ICARDA's headquarters, where they had the opportunity to interact with the centre's top management. Yet the farmers' positive feedback failed to convince other scientists to follow the path of the centre's barley improvement programme. PPB never became ICARDA's main method for plant breeding.

\subsection{From Participatory to Evolutionary Plant Breeding}

Although the term evolutionary plant breeding (EPB) was first used in 1956 (Suneson, 1956), the idea of exploiting the advantages of genetic heterogeneity, in the form of either mixtures, obtained by mixing the seed of different varieties of the same crop, or populations, obtained by mixing the seed derived from crossing different varieties of the same crop (Wolfe \& Ceccarelli, 2019), was much older (Harlan \& Martini, 1929, 1938).

After those early studies, a vast body of research has been published, demonstrating how evolutionary populations (EPs) and mixtures are able to evolve and adapt their phenology to the area of cultivation by becoming earlier maturing or later maturing depending on the adaptative advantages of these traits (Allard \& Hansche, 1964), to increase their yield (Patel et al., 1987; Rasmusson et al., 1967; Soliman \& Allard, 1991; Suneson, 1956), their yield stability (Allard, 1961) and their height (Suneson \& Wiebe, 1942). 
A major benefit of EPs and mixtures is their ability to control the spread of diseases because the presence of plants with different levels of resistance and/or susceptibility makes the diffusion of the disease much slower than in a genetically uniform crop (Finckh \& Wolfe, 2006; Finckh et al., 2000; Ibrahim \& Barret, 1991; McDonald et al., 1988; Mulumba et al., 2012; Mundt, 2002; Simmonds, 1962; Smithson \& Lenné, 1996).

More recently, several papers confirmed that EPs do adapt to different geographical areas via phenological adaptation (Goldringer et al., 2006), that they tend to perform better than uniform varieties in years affected by drought (Danquah \& Barrett, 2002) and that they can combine higher yield and higher yield stability (Raggi et al., 2017). Eventually, the evolutionary potential of EPs and mixtures, if widely adopted, can represent a fast and economic solution to the complexity of climate change (Ceccarelli \& Grando, 2020a). It is therefore surprising that, despite all the scientific evidence, there has been very little practical agricultural use of EPs beyond their discussion in scientific papers.

Because of the difficulties in institutionalizing PPB, in 2008, while working at ICARDA, two of us (S.C. and S.G.) decided to constitute an EP of barley (Hordeum vulgare L.) by mixing the seed of the progenies of 1600 crosses. This EP was then planted in Syria, Eritrea, Jordan, Algeria and Iran-some of the countries where a network of farmers had already enhanced their diversity management skills through participation in PPB programmes. While two additional EPs, one with bread wheat (Triticum aestivum L.) and one with durum wheat (Triticum turgidum L. subsp. durum [Desf.] Husn.) were developed at ICARDA, the barley EP planted in Iran by two farmers in Kermanshah and Semnan provinces caught the attention of an Iranian breeder at the Dryland Agricultural Research Institute (DARSI) in Kermanshah, who decided to make a local bread wheat population.

\subsection{The Evolutionary Populations in Iran}

Iranian farmers who planted the barley EP were so satisfied with the population's performance that they shared the seed with farmers in other provinces, both through the PPB programme of Iran's Centre for Sustainable Development and Environment (CENESTA), and informally with neighbours, friends and relatives. This initial work with EPs in Iran by CENESTA, was supported by a small grant from the International Fund for Agricultural Development (IFAD) and within a few years, from 2010 


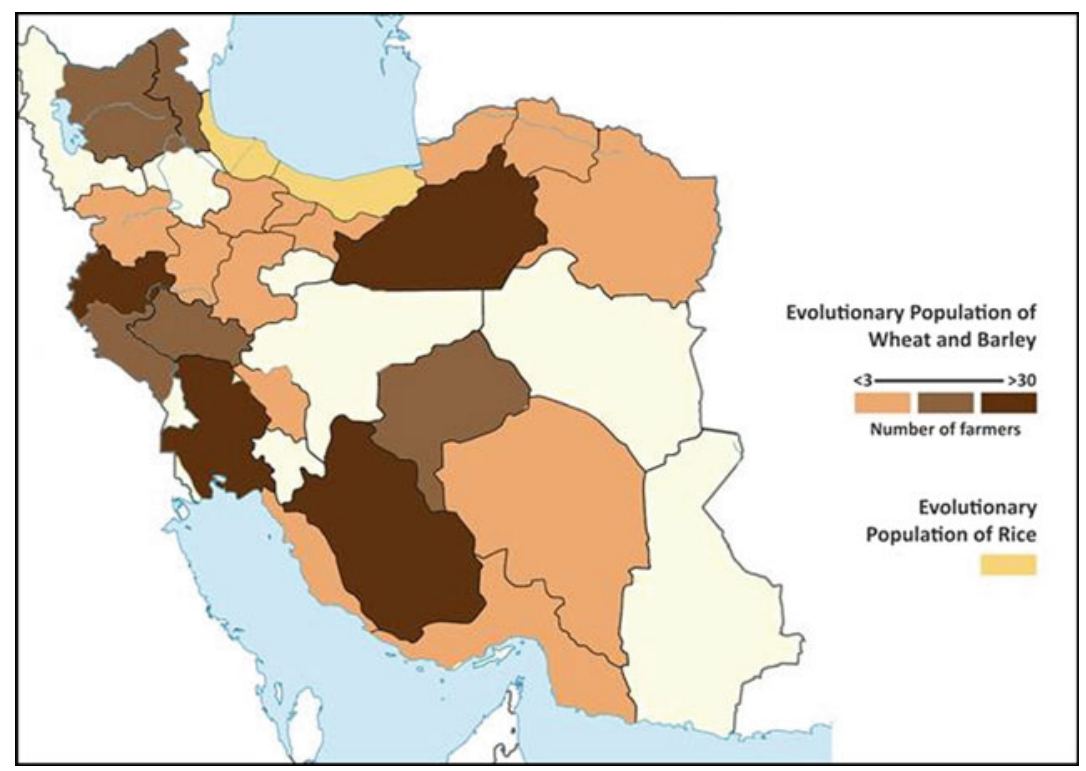

Fig. 8.1 Distribution of wheat, barley and rice evolutionary populations in Iran

to 2014 , the populations covered several hundred hectares in 17 provinces and involved some 150 farmers (see Fig. 8.1).

EPs in Iran are mostly cultivated under rainfed conditions. But they are grown, too, by farmers in irrigated areas who are facing water shortages, because the populations are recognized as more resistant to water scarcity and drought than modern varieties.

Indeed, most of the Iranian farmers in marginal ${ }^{1}$ areas and under lowinput and rainfed conditions reported that EPs had higher yields than modern varieties and showed good yield stability. They are more resistant to biotic and abiotic stresses such as pests and diseases, weeds, drought, water shortage cold, heat, strong winds and hail, and can grow better than uniform varieties in low-fertility soils. In addition, many farmers reported the EP seeds as very beautiful and, in terms of quality, health and thousand-kernel weight, superior to local, improved or modern varieties.

${ }^{1}$ Marginal here is used to mean poor soil, low rainfall with low expected agricultural productivity, but also socially marginal with limited opportunity for other jobs. 
There are also reports on food and feed quality in these populations. For example, baking bread with flour from EPs has been found to improve its smell and taste, as well as nutritional qualities. In addition, nomads or herders have noted that as livestock feed, the grains or straw of the ICARDA barley EP, compared with conventional feed, accelerates growth in lambs and improves the quality of milk. All of these characteristics encourage farmers to use and multiply these populations and cultivate them regularly as a main crop.

Our original aim regarding EPs was to endow farmers with a wealth of genetic diversity from which they could select, independently in each location, varieties adapted to their physical, social and market conditions. One unexpected outcome of the IFAD project, however, was that the bread obtained from the bread wheat EP-cultivated without any further selection-soon became the basis of a profitable business. That opened up the possibility of using the populations as crops. There were a number of advantages to this approach: it exploited the evolutionary ability of the population to slowly adapt to both short- and long-term climate change with the complexity described earlier; it enabled the development of an independent seed supply, because there is no better seed than the one that continuously adapts to farmer's conditions; and it generated income.

In the EPB programme in Iran, the EPs reach farmers through various stakeholders, but in most cases, the seeds are distributed through a farmer-saved seed system. CENESTA had and continues to have a facilitating role in ensuring that farmers, breeders and researchers can connect, and also ensures that EPs are steadily disseminated among groups such as farmers, research stations and extension centres.

In the first year under the programme, each farmer receives 4-10 kilograms of one of the EPs, depending on the amount of seed available and the severity of environmental and climatic conditions in different regions. Farmers in more environmentally stressed and less productive areas are given more seeds; thus, if they lose most of the genotypes within the EP, they have a higher probability that a sufficient number survive from which to collect spikes for next year's cultivation. In the following year, and if farmers are satisfied with the EP's results, they will start seed multiplication to produce enough seeds and to expand the area under cultivation. On average, after four years, the farmers who had the most success with the crop and consequently with more seed availability will start exchanging the seed of the EPs, even up to several tons, with other farmers in their region or those with similar environmental and climatic conditions (see Fig. 8.2). 


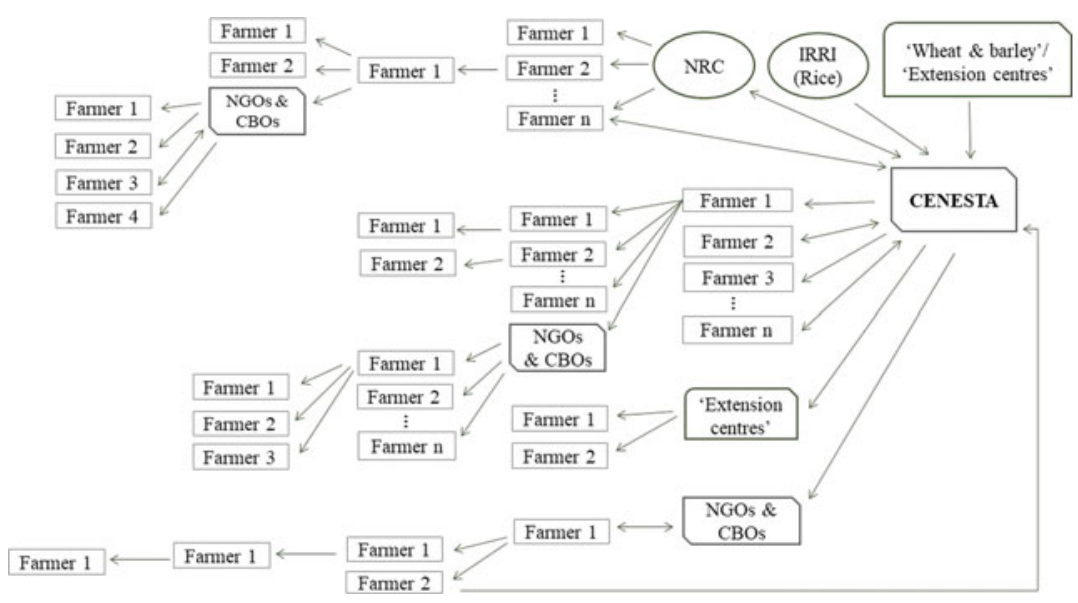

Fig. 8.2 Farmer to farmer diffusion of evolutionary populations (EPs) in Iran: the barley EP originated from ICARDA, the bread wheat EP originated from DARSI and the EP of rice originated from Iranian landraces received from IRRI. The EPs were initially distributed by CENESTA either directly to farmers or through other organizations $(\mathrm{NRC}=$ National Research Centre, NGOs $=$ NonGovernmental Organizations, $\mathrm{CSOs}=$ Civil Society Organizations)

In recent years, both the number of farmers and the area under cultivation with EPs have increased, although monitoring and estimating that increase is not easy, given the complexity and breadth of farm-saved seed systems. It is known, however, that hundreds of farmers in different parts of Iran do cultivate EPs and extend the area under cultivation every year, and also exchange their seed with other farmers in their region.

The success of EPB in Iran with wheat and barley suggested to CENESTA researchers that the same approach might be used with rice, one of the country's most important food crops. Beginning in 2013, CENESTA imported 210 Iranian rice landraces from the gene bank of the International Rice Research Institute (IRRI) and multiplied them at the Research Station of the Rice Research Iranian Institute (RRII). Three evolutionary mixtures were then developed, by mixing the seed of all the landraces (200 genotypes), only the early maturing varieties (115 genotypes) and the late-maturing varieties ( 85 genotypes). These were distributed to some farmers and were also used in a project between RRII and CENESTA and, in 2019, in a new IFAD-funded project (see Sect. 8.6). 


\subsection{SMARt Food from Iran's Evolutionary Populations}

EPs may be considered to be smart crops-healthy for the consumers, as well as produced and distributed in an environmentally sustainable way and profitable for the farmers.

The benefits of EPs for consumers are manifold. The bread made using the first EP of bread wheat grown in Iran was highly appreciated by consumers for its digestibility, lengthy shelf life, flavour and aroma. Similar developments took place in Italy beginning in 2010 (see Sect. 8.6).

Regarding EPs' benefits for the environment, their diversity renders them resistant to diseases, insects and weeds, making the use of pesticides unnecessary; that in turn reduces emissions and helps to mitigate the effects of climate change. As the EPs evolve, they also adapt to the unpredictable and location-specific complexities of climate change.

EPs are good, too, for the farmers who grow them. Their robustness and resilience reduce production costs, while the popularity of the products derived from the different wheat EPs brings in income.

Even as the cultivation of EPs increases, and the products made with them reach more organic shops, researchers are still drawn to the science of populations (Ceccarelli \& Grando, 2020a; Raggi et al., 2017). The scientific literature shows how populations evolve by becoming more productive and disease-resistant, how they ripen in harmony with the environment in which they evolve and how their yields become more stable year on year.

\subsection{Evolutionary Populations in OTher Countries}

The success of EPs in Iran had two major international consequences. The first was in Italy, where the three ICARDA EPs arrived in 2010 via the Italian Association of Organic Agriculture, and quickly spread to farms throughout the country. The Italian experience of the bread wheat EP mirrored Iran's, and in a few years farmers in most regions of Italy (Fig. 8.3) were growing the EP, millers were selling the flour, bakeries were producing much-appreciated bread from it and organic shops and restaurants were selling both bread and flour. The same happened with a durum wheat EP, grown for use in pasta, although not yet as widely as the bread wheat EP. 


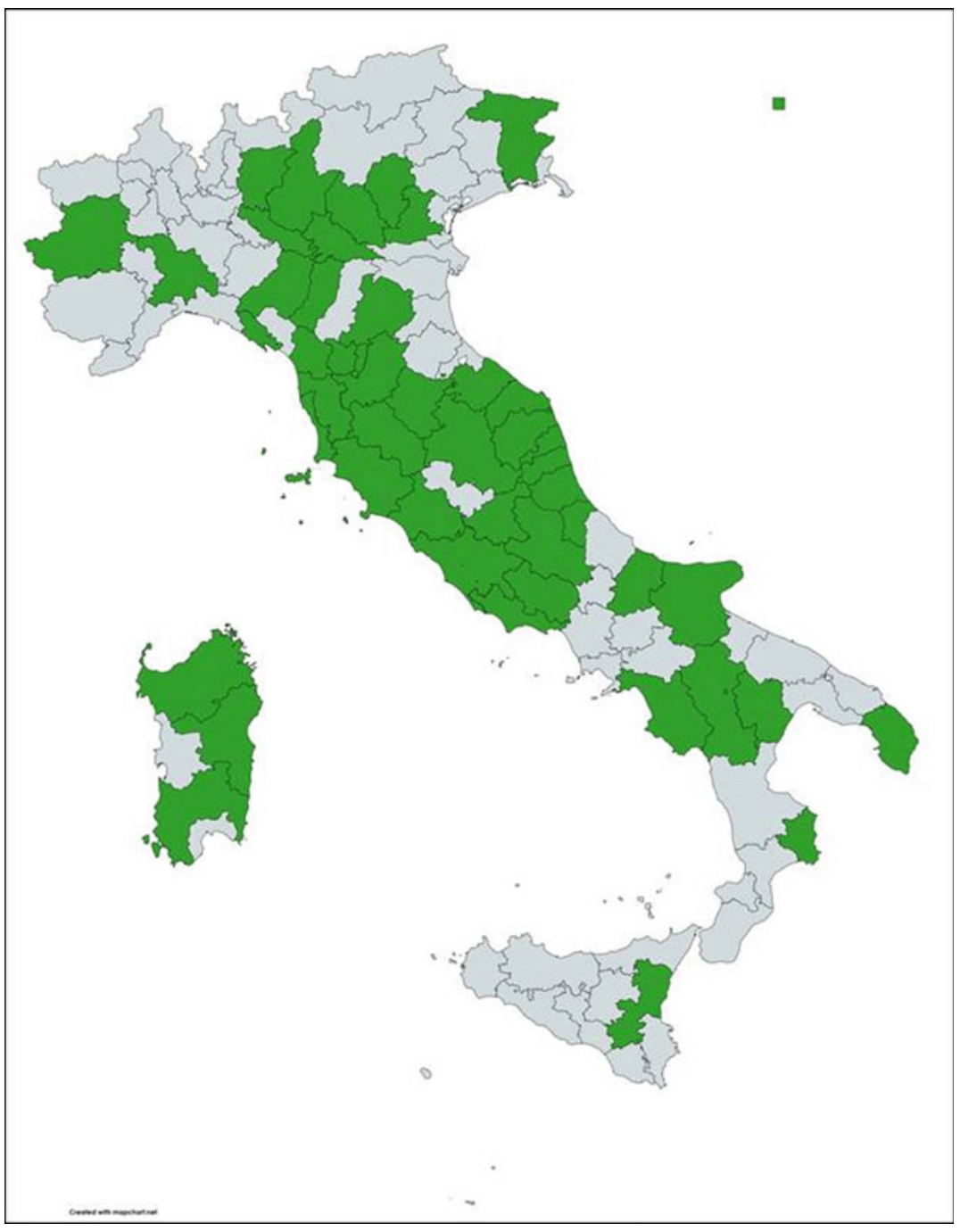

Fig. 8.3 The spread of evolutionary populations of bread wheat, durum wheat and barley in Italy from 2010 to present 
The second consequence was that IFAD, following the success of its small grant project (see Sect. 8.4), decided to invest in evolutionary plant breeding and financed a four-year (2018-2022) project in Africa (Uganda and Ethiopia), the Near East (Jordan and Iran) and Asia (Nepal and Bhutan) implemented by Bioversity International. The project covers important staple crops such as wheat (Ethiopia, Jordan and Iran), rice (Iran, Nepal and Bhutan), bean (Uganda, Nepal and Bhutan) and barley (Ethiopia, Jordan and Iran). At the time of writing, the project has ended its third year's trials planted in 46 locations across the 6 countries with over $450 \mathrm{EPs}$, using local and improved varieties as controls.

\subsection{Conclusions}

Evolutionary-participatory plant breeding can be considered as a further step, compared with PPB, towards what Jack Kloppenburg (2010) has defined as "repossession". In fact, evolutionary-participatory plant breeding allows farmers to autonomously manage genetic diversity without institutional support. This does not mean that Research institutions are excluded from the process; only that their participation is not indispensable. Institutions may play a role in developing populations by crossing a given number of varieties or simply making available to farmers the remnant seed of early segregating populations. Beyond providing farmers with the diversity offered by EPs, institutions may develop a decentralized-participatory breeding programme distributing EPs assembled by them to farmers representing the target population of environments the programme aims to serve as, for example, farmers practising organic agriculture in geographical areas characterized by different rainfall, elevation, disease pressure and weed but also different market opportunities (Ceccarelli \& Grando, 2020c). Under such a programme, farmers conduct the selection process in their own fields, and institutions multiply the selected material and organize field trials.

The examples of Iran, Italy and other countries indicate that EPs can be defined as "smart crops" because they represent a triple "win". They are good for the planet, as they reduce the use of chemical inputs and allow adaptation to the complexity of climate change; they are good for the consumer as they produce healthy food and they are good for farmers as they generate income.

The main hurdle in the diffusion of EPs is seed laws. EPs do not meet the Distinctness, Uniformity and Stability (DUS) requirements for their 
official registration and marketing, established by the International Union for the Protection of New Varieties of Plants (UPOV). However, the European Union has recently taken two interesting steps.

First, a Commission Implementing Decision of 18 March 2014 pursuant to Council Directive 66/402/EEC in Europe made it possible to market experimentally heterogeneous materials, namely evolutionary populations and mixtures as defined earlier, of wheat, barley, oat and maize up to 28 February 2021. Secondly, a newly approved regulation of organic agriculture, to come into effect on 1 January 2022, will make it possible to use heterogeneous material in organic farming. That will not only enable organic farmers to use their own seed, but they will also be able to use EPs in decentralized-participatory breeding programmes to develop varieties and/or populations specifically adapted to organic agriculture, as described above.

Acknowledgements The authors thank IFAD for supporting the initial activities in Iran and for financing the project "Use of genetic diversity and Evolutionary Plant Breeding for enhanced farmer resilience to climate change, sustainable crop productivity, and nutrition under rainfed conditions in Uganda, Ethiopia, Jordan, Iran, Bhutan and Nepal". We also thank ICARDA for supporting the development of the initial EPs; IRRI for facilitating the introduction of Iranian rice landraces; Dr. Reza Hagparast for his support; Bioversity International for successfully implementing the IFAD project; the farmers in several provinces in Iran; and the CENESTA team (Mobina Nourmohamadian, Mehdi Esmaeli, Yashar Hassannejad, Hanie Moghani and Soheil Hosseinzadeh) for carrying out most of the fieldwork.

\section{REFERENCES}

Allard, R. W. (1961). Relationship between genetic diversity and consistency of performance in different environments. Crop Science, 1(2), 127-133. https:// doi.org/10.2135/cropsci1961.0011183X000100020012x

Allard, R. W., \& Hansche, P. E. (1964). Some parameters of population variability and their implications in plant breeding. Advances in Agronomy, 16, 281-325. https://doi.org/10.1016/S0065-2113(08)60027-9

Baranski, M. R. (2015). Wide adaptation of Green Revolution wheat: International roots and the Indian context of a new plant breeding ideal, 1960-1970. Studies in History and Philosophy of Biological and Biomedical Sciences, 50, 41-50. https://doi.org/10.1016/j.shpsc.2015.01.004 
Bonnin, I., Bonneuil, C., Goffaux, R., Montalent, P., \& Goldringer, I. (2014). Explaining the decrease in the genetic diversity of wheat in France over the 20th century. Agriculture, Ecosystems \& Environment, 195, 183-192. https:// doi.org/10.1016/j.agee.2014.06.003

Ceccarelli, S. (1989). Wide adaptation: How wide? Euphytica, 40, 197-205. https://doi.org/10.1007/BF00024512

Ceccarelli, S. (2015). Efficiency of plant breeding. Crop Science, 55, 87-97. https://doi.org/10.2135/cropsci2014.02.0158

Ceccarelli, S., \& Grando, S. (2020a). Evolutionary plant breeding as a response to the complexity of climate change. iScience, 23(12), 101815. https://doi. org/10.1016/j.isci.2020.101815

Ceccarelli, S., \& Grando, S. (2020b). Participatory plant breeding: Who did it, who does it and where? Experimental Agriculture, 56(1), 1-11. https://doi. org/10.1017/S0014479719000127

Ceccarelli, S., \& Grando, S. (2020c). Organic agriculture and evolutionary populations to merge mitigation and adaptation strategies to fight climate change. South Sustainability, 1(2), e002. https://doi.org/10.21142/SS-0102-202 $0-013$

Ceccarelli, S., Galiè, A., \& Grando, S. (2013). Participatory breeding for climate change-related traits. In C. Kole (Ed.), Genomics and breeding for climateresilient crops (Vol. 1, pp. 331-376). Springer-Verlag. https://doi.org/10. 1007/978-3-642-37045-8_8

Danquah, E. Y., \& Barrett, J. A. (2002). Grain yield in composite cross five of barley: Effects of natural selection. Journal of Agricultural Science, 138(2), 171-176. https://doi.org/10.1017/S0021859601001678

Díaz, S., Fargione, J., Chapin, F. S. III, \& Tilman, D. (2006). Biodiversity loss threatens human well-being. PLoS Biology, 4(8), e277. https://doi.org/10. 1371/journal.pbio.0040277

Dwivedi, S. L., Ceccarelli, S., Blair, W. M., Upadhyaya, H. D., Are, A. K., \& Ortiz, R. (2016). Landrace germplasm for improving yield and abiotic stress adaptation. Trends in Plant Science, 21(1), 31-42. https://doi.org/10.1016/ j.tplants.2015.10.012

Finckh, M. R., Gacek, E. S., Goyeau, H., Lannou, C., Merz, U., Mundt, C. C., Munk, L., Nadziak, J., Newton, A., de Vallavieille-Pope, C., \& Wolfe, M. S. (2000). Cereal variety and species mixtures in practice, with emphasis on disease resistance. Agronomy for Sustainable Development, 20, 813-837. https://doi.org/10.1051/agro:2000177

Finckh, M. R., \& Wolfe, M. S. (2006). Diversification strategies. In B. Cooke, D. Jones, \& B. Kaye (Eds.), The epidemiology of plant diseases (pp. 269-307). Springer Netherlands. https://doi.org/10.1007/1-4020-4581-6

Fisher, M. C., Hawkins, N. J., Sanglard, D. M., \& Gurr, S. J. (2018). Worldwide emergence of resistance to antifungal drugs challenges human health and food 
security. Science, 360(6390), 739-742. https://doi.org/10.1126/science.aap 7999

Galiè, A., Hack, B., Manning-Thomas, N., Pape-Christiansen, A., Grando, S., \& Ceccarelli, S. (2009). Evaluating knowledge sharing in research: The International Farmers' Conference organized at ICARDA. Knowledge Management for Development Journal, 5(2), 108-126. https://doi.org/10.1080/194741 90903387666

Goldringer, I., Prouin, C., Rousset, M., Galic, N., \& Bonnin, I. (2006). Rapid differentiation of experimental populations of wheat for heading time in response to local climatic conditions. Annals of Botany, 98(4), 805-817. https://doi.org/10.1093/aob/mcll60

Harlan, H. V., \& Martini, M. L. (1929). A composite hybrid mixture. Agronomy Journal, 21(4), 487-490. https://doi.org/10.2134/agronj1929.000219620 $02100040014 \mathrm{x}$

Harlan, H. V., \& Martini, M. L. (1938). The effect of natural selection in a mixture of barley varieties. Journal of Agricultural Research, 57(3), 189-199.

Ibrahim, K. M., \& Barret, J. A. (1991). Evolution of mildew resistance in a hybrid bulk population of barley. Heredity, 67, 247-256. https://doi.org/ 10.1038/hdy. 1991.86

Isbell, F., Craven, D., Connolly, J., Loreau, M., Schmid, B., Beierkuhnlein, C., ... \& Eisenhauer, N. (2015). Biodiversity increases the resistance of ecosystem productivity to climate extremes. Nature, 526(7574), 574-577. https://doi. org/10.1038/nature 15374

Keneni, G., Bekele, E., Imtiaz, M., \& Dagne, K. (2012). Genetic vulnerability of modern crop cultivars: Causes, mechanism and remedies. International Journal of Plant Research, 2(3), 69-79. https://doi.org/10.5923/j.plant.201 20203.05

Kloppenburg, J. (2010). Impeding dispossession, enabling repossession: Biological open source and the recovery of seed sovereignty. Journal of Agrarian Change, 10(3), 367-388. https://doi.org/10.1111/j.1471-0366.2010.002 75.x

McDonald, B. A., Allard, R. W., \& Webster, R. K. (1988). Responses of two, three, and four component barley mixtures to a variable pathogen population. Crop Science, 28(3), 447-452. https://doi.org/10.2135/cropscil988. $0011183 \times 002800030003 \mathrm{x}$

Mulumba, J. W., Nankya, R., Adokorach, J., Kiwuka, D., Fadda, C., De Santis, P., \& Jarvis, D. I. (2012). A risk-minimizing argument for traditional crop varietal diversity use to reduce pest and disease damage in agricultural ecosystem of Uganda. Agriculture, Ecosystem and the Environment, 157, 70-86. https://doi.org/10.1016/j.agee.2012.02.012 
Mundt, C. C. (2002). Use of multiline cultivars and cultivar mixtures for disease management. Annual Review of Phytopathology, 40, 381-410. https://doi. org/10.1146/annurev.phyto.40.011402.113723

Patel, J. D., Reinbergs, E., Mather, D. E., Choo, T. M., \& Sterling, J. D. E. (1987). Natural selection in a doubled-haploid mixture and a composite cross of barley. Crop Science, 27(3), 474-479. https://doi.org/10.2135/cropsc il $987.0011183 \times 002700030010 \mathrm{x}$

Raggi, L., Ciancaleoni, S., Torricelli, R., Terzi, V., Ceccarelli, S., \& Negri, V. (2017). Evolutionary breeding for sustainable agriculture: Selection and multi-environment evaluation of barley populations and lines. Field Crops Research, 204, 76-88. https://doi.org/10.1016/j.fcr.2017.01.011

Rasmusson, D. C., Beard, B. H., \& Johnson, F. K. (1967). Effect of natural selection on performance of a barley population. Crop Science, 7, 543-543. https://doi.org/10.2135/cropsci1967.0011183X000700050042x

Rhoades, R. E., \& Booth, R. H. (1982). Farmer-back-to-farmer: A model for generating acceptable agricultural technology. Agricultural Administration, 11, 127-137. https://doi.org/10.1016/0309-586X(82)90056-5

Simmonds, N. W. (1962). Variability in crop plants, its use and conservation. Biological Reviews, 37(3), 422-465. https://doi.org/10.1111/j.1469-185X. 1962.tb01620.x

Smithson, J. B., \& Lenné, J. M. (1996). Varietal mixtures: A viable strategy for sustainable productivity in subsistence agriculture. Annals of Applied Biology, 128(1), 127-158. https://doi.org/10.1111/j.1744-7348.1996.tb07096.x

Soliman, K. M., \& Allard, R. W. (1991). Grain yield of composite cross populations of barley: Effects of natural selection. Crop Science, 31(3), 705-708. https://doi.org/10.2135/cropsci1991.0011183X003100030032x

Suneson, C. A. (1956). An evolutionary plant breeding method. Agronomy Journal, 48(4), 188-191. https://doi.org/10.2134/agronj1956.000219620 $04800040012 x$

Suneson, C. A., \& Wiebe, G. A. (1942). Survival of barley and wheat varieties in mixtures. Journal of the Agronomy Society of America, 34(11), 1052-1056. https://doi.org/10.2134/agronj1942.00021962003400110010x

van der Wouw, M., Kik, C., van Hintum, T., van Treuren, R., \& Visser, B. (2010). Genetic erosion in crops: Concept, research results and challenges. Plant Genetic Resources, 8(1), 1-15. https://doi.org/10.1017/S14792621 09990062

Wolfe, M. S., \& Ceccarelli, S. (2019). The increased use of diversity in cereal cropping requires more descriptive precision. Journal of the Science of Food and Agriculture, 100(11), 4119-4123. https://doi.org/10.1002/jsfa.9906 
Open Access This chapter is licensed under the terms of the Creative Commons Attribution 4.0 International License (http://creativecommons.org/licenses/ by $/ 4.0 /$ ), which permits use, sharing, adaptation, distribution and reproduction in any medium or format, as long as you give appropriate credit to the original author(s) and the source, provide a link to the Creative Commons license and indicate if changes were made.

The images or other third party material in this chapter are included in the chapter's Creative Commons license, unless indicated otherwise in a credit line to the material. If material is not included in the chapter's Creative Commons license and your intended use is not permitted by statutory regulation or exceeds the permitted use, you will need to obtain permission directly from the copyright holder.

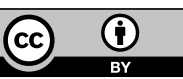

